\title{
A phase II trial of small-dose bortezomib, lenalidomide and dexamethasone (sVRD) as consolidation/maintenance therapy in patients with multiple myeloma
}

\author{
Soushi Ibata ${ }^{1} \cdot$ Tsutomu Sato $^{1} \cdot$ Hiroyuki Kuroda $^{2} \cdot$ Yasuhiro Nagamachi $^{3} \cdot$ Satoshi Iyama $^{1} \cdot$ Akihito Fujimi $^{4} \cdot$ \\ Yusuke Kamihara $^{1}$ - Yuichi Konuma ${ }^{5} \cdot$ Masahiro Yoshida $^{1} \cdot$ Ayumi Tatekoshi $^{1} \cdot$ Akari Hashimoto $^{1}$. \\ Hiroto Horiguchi $^{1} \cdot$ Kaoru Ono $^{1} \cdot$ Kazuyuki Murase $^{1} \cdot$ Kohichi Takada $^{1} \cdot$ Koji Miyanishi $^{1} \cdot$ Masayoshi Kobune $^{1} \cdot$ \\ Yasuo Hirayama' ${ }^{6}$ Junji Kato ${ }^{1}$
}

Received: 26 January 2016 / Accepted: 6 October 2016 / Published online: 13 October 2016

(C) The Author(s) 2016. This article is published with open access at Springerlink.com

\begin{abstract}
Purpose Consolidation/maintenance therapy induces deep remission in patients with multiple myeloma (MM); however, the most suitable regimen has been under investigation. The combination therapy with bortezomib, lenalidomide and dexamethasone (VRD) is a powerful regimen for relapsed/refractory as well as newly diagnosed MM as an induction therapy. However, severe adverse events (AEs) may become a problem when VRD is introduced without dose reduction as a consolidation/maintenance therapy.

Methods In this single-arm phase II study, we evaluated the efficacy of small-dose VRD regimen (sVRD) in the consolidation/maintenance setting. Sixteen patients who had partial response (PR) or better after any induction therapy were enrolled. Patients received at least six 28-day cycles of subcutaneous bortezomib $\left(1.3 \mathrm{mg} / \mathrm{m}^{2}\right.$ on days 1 and 15$)$, lenalidomide (10 $\mathrm{mg}$ on days $1-21)$ and dexamethasone (40 $\mathrm{mg}$ on days $1,8,15$ and 22).
\end{abstract}

Tsutomu Sato

tsutomus@sapmed.ac.jp

1 Department of Medical Oncology and Hematology, Sapporo Medical University School of Medicine, South-1 West-16, Chuo-ku, Sapporo, Japan

2 Gastroenterology and Hematology/Clinical Oncology, Internal Medicine, Steel Memorial Muroran Hospital, Muroran, Japan

3 Department of Hematology, Kiyota Hospital, Sapporo, Japan

4 Department of Hematology and Oncology, Oji General Hospital, Tomakomai, Japan

5 Department of Hematology and Oncology, Asahikawa Red Cross Hospital, Asahikawa, Japan

6 Division of Internal Medicine, Higashi Sapporo Hospital, Sapporo, Japan
Results The overall response rate and the complete response (CR) rate were 100 and $43.8 \%$, respectively. In particular, one patient with $\mathrm{CR}$ and two patients with very good PR at enrollment achieved stringent CR during 6 courses of sVRD. With a median follow-up time of 29.4 months, the median progression-free survival (PFS) and overall survival (OS) were not reached, while the PFS and OS rates at 2.5 years were 66.6 and $77.3 \%$, respectively. Univariate analysis demonstrated that disease progression as a reason for discontinuation of sVRD had a negative impact on OS. There were no grade 3 or 4 hematologic or nonhematologic AEs.

Conclusion Our sVRD regimen as a consolidation/maintenance therapy was highly effective and well tolerable.

Keywords Multiple myeloma $\cdot$ Consolidation/ maintenance $\cdot$ Bortezomib $\cdot$ Lenalidomide .

Dexamethasone $\cdot$ VRD

\section{Introduction}

Over the past 10 years, the median overall survival (OS) of patients with multiple myeloma (MM) has considerably increased due to the use of autologous hematopoietic stem cell transplantation (HSCT) and the introduction of the immunomodulatory drugs, thalidomide and lenalidomide, and the proteasome inhibitor, bortezomib, in transplanteligible and transplant-ineligible patients [1].

In order to consolidate and maintain the outcome after induction therapy with these novel agents, consolidation/ maintenance therapy has been an attractive choice. Consolidation (two to four cycles of combination therapies) and maintenance (continuous therapy, usually with single agents, until the time of disease progression) are commonly 
used in clinical practice after induction therapy, although no specific guidelines are available [2].

There have been many trials to support the use of consolidation/maintenance to maintain the response achieved after autologous HSCT or conventional treatments and to improve patient survival with single agent or combination therapy: thalidomide [3-8], lenalidomide [9-12], bortezomib [13], bortezomib plus thalidomide [14, 15] and bortezomib, thalidomide plus dexamethasone [16, 17]. However, no definitive information is available regarding which drug or which combination of drugs is the most favorable for consolidation/maintenance.

Concerning this matter, Kikuchi et al. [18] published an informative study using in vitro isobologram analysis. They demonstrated that lenalidomide has strong combined effects with bortezomib on myeloma cells in the presence of stromal cells. The bortezomib-induced up-regulation of CCAAT/enhancer-binding protein homologous protein (CHOP), a pro-apoptotic transcription factor, was readily enhanced by lenalidomide in contact with stromal cells. Their findings are compatible with the report that the overall response rate (ORR) (i.e., very good partial response or better) of the combination of bortezomib, lenalidomide and dexamethasone (VRD) was higher than those of bortezomib, doxorubicin and dexamethasone (PAD), bortezomib, thalidomide and dexamethasone (VTD), or cyclophosphamide, bortezomib and dexamethasone (CVD) in newly diagnosed myeloma patients [19].

The combination regimen of VRD was first evaluated in patients with relapsed or relapsed/refractory MM in a phase I, dose-escalation study by Richardson et al. [20]. Then, they reported a phase II study to evaluate the efficacy and safety of VRD in the same relapsed or relapsed/refractory setting [21]. Also in a frontline setting, they reported favorable toxicity and promising response and survival of patients treated with the VRD regimen in a phase I/II study [22]. Some other reports confirmed the efficacy of the VRD regimen as a frontline [23] or second-line treatment [24, 25].

Especially, Roussel et al. [23] evaluated the efficacy of three courses of the VRD regimen as an induction treatment for previously untreated patients; their VRD regimen consisted of 3-week cycles of intravenous bortezomib $1.3 \mathrm{mg} / \mathrm{m}^{2}$ on days $1,4,8$ and 11 ; oral lenalidomide $25 \mathrm{mg}$ on days 1 to 14 ; and oral dexamethasone $40 \mathrm{mg}$ on days 1 , 8 and 15 . They reported that the ORR at the completion of induction therapy was $58 \%$.

In consideration of this high efficacy, the combination of bortezomib, lenalidomide and dexamethasone is attractive for consolidation/maintenance treatment; however, adverse events (AEs) were not negligible with the full dosage of their VRD regimen. The most common toxicities with the VRD regimen were neurologic and hematologic, including grade $1-2$ sensory neuropathy (55\%), grade $3-4$ neutropenia $(35 \%)$ and thrombocytopenia (13\%) [23].

Therefore, we conducted a phase II study reported herein evaluating the efficacy and safety of small-dose VRD (sVRD) in the consolidation/maintenance setting.

\section{Methods}

\section{Study design and objective}

The aim of this multicenter, open-label, single-arm, phase II study was to determine the efficacy and safety of sVRD in Japanese patients with MM in the consolidation/maintenance setting. The primary end point of this study was the best ORR during 6 courses of sVRD. Secondary end points included progression-free survival (PFS), OS and safety. This study was conducted according to the Declaration of Helsinki and was approved by the institutional review board of each participating center. The institutional review board-approved consent form was signed by all patients before participating in this study. This trial is registered at www.umin.ac.jp (\#UMIN8236).

\section{Patients}

Eligible patients were age $\geq 20$ and $\leq 80$ years, with measurable symptomatic MM. Patients must have received at least 1 prior regimen and achieved at least a partial response (PR) by the International Myeloma Working Group (IMWG) Uniform Response Criteria. Other eligibility criteria included Eastern Cooperative Oncology Group (ECOG) performance status (PS) of 0-2, and an expected survival of more than 3 months. Adequate pulmonary, cardiac, renal and hepatic functions were required.

\section{Treatment}

Patients received subcutaneous bortezomib $\left(1.3 \mathrm{mg} / \mathrm{m}^{2}\right.$ on days 1 and 15), oral lenalidomide (10 mg on days 1-21) and oral dexamethasone (40 $\mathrm{mg}$ on days $1,8,15$ and 22). The course was repeated every 4 weeks for 6 cycles. Patients with at least a PR at the end of cycle 6 could continue sVRD treatment. Patients discontinued therapy if they experienced progressive disease (PD) or unacceptable toxicity, if no more additional benefits could be expected or if the patient/investigator decided to discontinue therapy for any reason. Dose adjustments were permitted based on grade 3 or 4 AEs or based on an investigator's decision; bortezomib could be reduced from 1.3 to $1.0 \mathrm{mg} / \mathrm{m}^{2}$, lenalidomide from 10 to $5 \mathrm{mg} /$ day and dexamethasone from 40 to $20 \mathrm{mg} /$ day. If a similar severity of toxicity occurred at the reduced dose, study treatment was discontinued. 
Table 1 Characteristics of the patients with MM who received the sVRD regimen

\begin{tabular}{|c|c|}
\hline Characteristic & All patients $(n=16)$ \\
\hline Age [mean (range)] & $67(53-78)$ \\
\hline Male sex $[n(\%)]$ & $11(68.8)$ \\
\hline $\begin{array}{l}\text { Mean time from diagnosis to enrollment } \\
\text { [months (range)] }\end{array}$ & $17(4-95)$ \\
\hline \multicolumn{2}{|l|}{$\operatorname{PS}[n(\%)]$} \\
\hline 0 & $8(50.0)$ \\
\hline 1 & $6(37.5)$ \\
\hline 2 & $2(12.5)$ \\
\hline \multicolumn{2}{|l|}{ Type of myeloma $[n(\%)]$} \\
\hline $\operatorname{IgG}$ & $10(62.5)$ \\
\hline $\operatorname{Ig} \mathrm{A}$ & $6(37.5)$ \\
\hline Kappa & $13(81.3)$ \\
\hline Lambda & $3(18.7)$ \\
\hline \multicolumn{2}{|l|}{ ISS stage at enrollment $[n(\%)]$} \\
\hline I & $13(81.3)$ \\
\hline II & $3(18.7)$ \\
\hline III & $0(0)$ \\
\hline \multicolumn{2}{|l|}{ D-S stage at enrollment $[n(\%)]$} \\
\hline I & $14(87.5)$ \\
\hline II & $0(0)$ \\
\hline III & $2(12.5)$ \\
\hline \multicolumn{2}{|l|}{ Cytogenetic abnormalities $^{\mathrm{a}}[n(\%)]$} \\
\hline del 17 & $1 / 11(9.1)$ \\
\hline$t(14 ; 16)$ & $0 / 7(0)$ \\
\hline del 13 & $4 / 9(44.4)$ \\
\hline$t(4 ; 14)$ & $3 / 7(42.9)$ \\
\hline \multicolumn{2}{|l|}{ Induction regimen $[n(\%)]$} \\
\hline Any use of dexamethasone & $14(87.5)$ \\
\hline Any use of bortezomib & $13(81.3)$ \\
\hline Any use of lenalidomide & $7(43.8)$ \\
\hline Any use of doxorubicin & $4(25.0)$ \\
\hline Any use of melphalan & $3(18.8)$ \\
\hline Any use of cyclophosphamide & $2(12.5)$ \\
\hline Radiation & $7(43.8)$ \\
\hline HSCT & $4(25.0)$ \\
\hline
\end{tabular}

ISS International Staging System, D-S Durie and Salmon, HSCT hematopoietic stem cell transplantation

${ }^{\text {a }}$ Data were obtained by fluorescence in situ hybridization (FISH)

Antiviral prophylaxis, bisphosphonates, aspirin thromboprophylaxis and erythropoietic agents were permitted during the study. Granulocyte colony-stimulating factor was also allowed.

\section{Assessment of efficacy}

Response assessments were conducted before enrollment and after each course of sVRD treatment. The ORR was defined as the proportion of patients whose best overall response was either a stringent complete response (sCR), complete response (CR), very good PR (VGPR) or PR based on responses as assessed using IMWG Uniform Response Criteria. sCR, CR, VGPR and PR required two consecutive assessments made at any time before progression or initiation of any new therapy. Patients were followed for disease progression and OS for up to 3 years after discontinuation or completion of therapy.

\section{Assessment of safety}

AEs were assessed at each visit and were graded according to National Cancer Institute Common Terminology Criteria (NCI-CTC) for AEs (Version 4.0). Data were collected until 30 days after the last dose of study drug, except for secondary primary malignancies (SPM) (which were assessed all along during follow-up). SPM was defined as any malignancy observed after introduction of sVRD treatment.

\section{Statistical methods}

The median follow-up time was estimated using the reverse Kaplan-Meier method. PFS was calculated as the time from the start of treatment to the first documentation of PD or death if the patient died as a result of any cause before progression. OS was calculated as the time from the start of treatment to death. The Kaplan-Meier method was used to estimate the survival distribution. Univariate survival analysis was performed using the Kaplan-Meier method. The significance of differences in survival curves was assessed with the log-rank test. Multivariable analysis (Cox proportional hazards regression model) of OS was carried out on all covariates that showed a significant association with OS in univariate analysis. All analyses were conducted using GraphPad Prism version 5.0 (GraphPad Software, La Jolla, CA) and EZE (Saitama Medical Center, Jichi Medical University; http://www.jichi.ac.jp/saitama-sct/SaitamaHP.files/ statmedEN.html) [26].

\section{Results}

\section{Patients and treatments}

From June 2012 until November 2013, 16 MM patients were enrolled at 4 sites in Japan. The data cutoff date for this analysis was March 10, 2015. Patient demographics and baseline characteristics are summarized in Table 1 . The median age was 67 years (range 53-78 years); 12 patients $(75.0 \%)$ were $>65$ years. Eleven patients $(68.8 \%)$ were male. The median time from diagnosis to enrollment 
Table 2 Treatment duration of the sVRD regimen

\begin{tabular}{lc}
\hline & All patients $(n=16)$ \\
\hline Completion of 6 courses $[n(\%)]$ & $16(100)$ \\
Mean treatment duration [courses (range)] & $8.0(6-28)$ \\
Reason for discontinuation $[n(\%)]$ & \\
Completion of 6 courses & $7(43.8)$ \\
Disease progression & $3(18.8)$ \\
Second primary malignancy (acute lymphoblastic leukemia) & $1(6.3)$ \\
Adverse events (pneumonia) & $1(6.3)$ \\
Others & $4(25.0)$ \\
\hline
\end{tabular}

Table 3 Best overall response during 6 courses of sVRD

\begin{tabular}{llllll}
\hline Status at enrollment & \multicolumn{5}{l}{ Best overall response } \\
\cline { 2 - 6 } & sCR & CR & VGPR & PR & PD \\
\hline sCR $(n=4)$ & 4 & 0 & 0 & 0 & 0 \\
CR $(n=1)$ & 1 & 0 & 0 & 0 & 0 \\
VGPR $(n=2)$ & 2 & 0 & 0 & 0 & 0 \\
PR $(n=9)$ & 0 & 0 & 1 & 8 & 0 \\
Total $(n=16)[n(\%)]$ & $7(43.8)$ & $0(0)$ & $1(6.3)$ & $8(50.0)$ & $0(0)$ \\
\hline
\end{tabular}

$s C R$ stringent complete response, $C R$ complete response, $V G P R$ very good partial response, $P R$ partial response, $P D$ progressive disease

was 17 months (range 4-95 months). ECOG PS was 0 in $50.0 \%, 1$ in $37.5 \%$ and 2 in $12.5 \%$ of the patients. They had either IgG $(62.5 \%)$ or IgA $(37.5 \%)$ myeloma and had either Kappa (81.3\%) or Lambda (18.7\%) light chain. After restaging at the time of enrollment, $81.3 \%$ of patients had stage I and $18.7 \%$ stage II according to the classification system of the International Staging System (ISS), and $87.5 \%$ had stage I and $12.5 \%$ stage III according to the system of Durie and Salmon (D-S). Fluorescence in situ hybridization (FISH) performed at the time of diagnosis showed that $1(9.1 \%)$ out of 11 patients had del 17, $4(44.4 \%)$ out of 9 del 13 and $3(42.9 \%)$ out of $7 t(4 ; 14)$. The induction therapies before enrollment in this study were as follows: $87.5 \%$ of patients were treated with dexamethasone, $81.3 \%$ bortezomib, $43.8 \%$ lenalidomide, $25.0 \%$ doxorubicin, $18.8 \%$ melphalan and $12.5 \%$ cyclophosphamide. $43.8 \%$ of patients had undergone radiation therapy. $25.0 \%$ of patients had undergone at least one HSCT.

\section{Duration of treatment}

All patients could complete 6 courses of sVRD treatment (Table 2). The median duration of sVRD treatment was 8.0 courses (range $6-28$ courses), with $56.3 \%(n=9)$ and $25.0 \%(n=4)$ undergoing $>6$ and $>12$ cycles, respectively. At the data cutoff date, all 16 patients had discontinued treatment. The reasons for treatment discontinuation were completion of 6 courses $(n=7,43.8 \%)$, disease progression $(n=3,18.8 \%)$, SPM of acute lymphoblastic leukemia (ALL) $(n=1,6.3 \%)$, AE of grade 2 pneumonia $(n=1$, $6.3 \%$ ) or other (patient refusal or physician preference) $(n=4,25.0 \%)$.

\section{Response}

All 16 patients were response-evaluable. The ORR during 6 courses of sVRD treatment is shown in Table $3.43 .8 \%$ had an sCR, $0 \% \mathrm{CR}, 6.3 \% \mathrm{VGPR}, 50.0 \% \mathrm{PR}$ and $0 \% \mathrm{PD}$. The ORR and CR rate (i.e., at least CR) were 100 and $43.8 \%$, respectively. In detail, at enrollment, 4 patients were determined to be in sCR, 1 in CR, 2 in VGPR and 9 in PR. During 6 courses of sVRD, 4 patients with sCR at enrollment remained in sCR. One patient with $\mathrm{CR}$ and 2 with VGPR achieved sCR. In 9 patients with PR, 1 achieved VGPR, but 8 remained in PR. Nevertheless, 2 out of 8 patients with PR after 6 courses of sVRD finally achieved VGPR or sCR after a total of 18 or 24 courses of sVRD, respectively. Status at enrollment of a patient with $\operatorname{del}(17 \mathrm{p})$ was PR, and his best overall response was the same PR. Table 4 demonstrates that all four patients (No. 5-8) who obtained deeper response during 6 courses of sVRD were treated without lenalidomide in induction therapies.

\section{PFS and OS}

With a median follow-up time of 29.4 months (range 16.133.1 months), 13 out of 16 patients are still alive, 11 of whom are progression-free for a maximum of 33.1 months. Three patients died and their cause of death was disease progression in all cases. One of these three patients who died had SPM of myelodysplastic syndrome (MDS). One had chromosomal abnormality of $\operatorname{del}(17 \mathrm{p})$. It is noteworthy that the three patients who discontinued sVRD treatment due to PD were the same three patients who died in spite of various post-study therapies. Figure 1 shows the Kaplan-Meier estimates of PFS and OS. The median PFS was not reached, and the 2.5-year PFS was $66.6 \%(95 \%$ confidence interval [CI] 36.9-84.8\%). The median survival 
Table 4 Best overall response and induction regime

\begin{tabular}{|c|c|c|c|c|c|c|c|c|c|c|}
\hline \multirow[t]{2}{*}{ Patient no. } & \multirow[t]{2}{*}{ Status at enrollment } & \multirow[t]{2}{*}{ Best overall response } & \multicolumn{8}{|c|}{ Induction regimen } \\
\hline & & & Bor & Len & Dex & Dox & Mel & CY & RT & HSCT \\
\hline 1 & $\mathrm{sCR}$ & $\mathrm{sCR}$ & & $\checkmark$ & $\checkmark$ & & & & $\checkmark$ & $\checkmark$ \\
\hline 2 & $\mathrm{sCR}$ & $\mathrm{sCR}$ & $\checkmark$ & $\checkmark$ & $\checkmark$ & & & & & $\checkmark$ \\
\hline 3 & $\mathrm{sCR}$ & $\mathrm{sCR}$ & $\checkmark$ & & $\sqrt{ }$ & & & & & \\
\hline 4 & $\mathrm{sCR}$ & $\mathrm{sCR}$ & $\checkmark$ & $\checkmark$ & $\checkmark$ & & & & $\checkmark$ & \\
\hline 5 & $\mathrm{CR}$ & $\mathrm{sCR}$ & $\checkmark$ & & $\checkmark$ & & & & & \\
\hline 6 & VGPR & $\mathrm{sCR}$ & $\checkmark$ & $\mathrm{O}$ & $\checkmark$ & & & $\checkmark$ & & \\
\hline 7 & VGPR & $\mathrm{sCR}$ & $\checkmark$ & & $\checkmark$ & & & & $\checkmark$ & \\
\hline 8 & PR & VGPR & $\checkmark$ & & $\checkmark$ & & $\checkmark$ & & & \\
\hline 9 & PR & PR & & $\checkmark$ & $\checkmark$ & $\checkmark$ & & & & $\checkmark$ \\
\hline 10 & PR & PR & $\checkmark$ & & & & $\checkmark$ & & & \\
\hline 11 & PR & PR & $\checkmark$ & $\checkmark$ & $\checkmark$ & $\checkmark$ & & & $\checkmark$ & \\
\hline 12 & PR & PR & $\checkmark$ & & & & $\checkmark$ & & & \\
\hline 13 & PR & PR & $\checkmark$ & $\checkmark$ & $\checkmark$ & $\checkmark$ & & & $\checkmark$ & \\
\hline 14 & PR & PR & & $\checkmark$ & $\checkmark$ & $\checkmark$ & & & & $\checkmark$ \\
\hline 15 & PR & PR & $\checkmark$ & & $\checkmark$ & & & & $\checkmark$ & \\
\hline 16 & PR & PR & $\checkmark$ & & $\checkmark$ & & & $\checkmark$ & $\checkmark$ & \\
\hline Total $(n=16)$ & 16 & 16 & 13 & 7 & 14 & 4 & 3 & 2 & 7 & 4 \\
\hline
\end{tabular}

Bor bortezomib, Len lenalidomide, Dex dexamethasone, Dox doxorubicin, $M e l$ melphalan, $C Y$ cyclophosphamide, $R T$ radiation, $H S C T$ hematopoietic stem cell transplantation

Fig. 1 Kaplan-Meier curves of PFS and OS of MM patients who received the $\mathrm{SVRD}$ regimen. a PFS (the median PFS was not reached). b OS (the median OS was not reached)
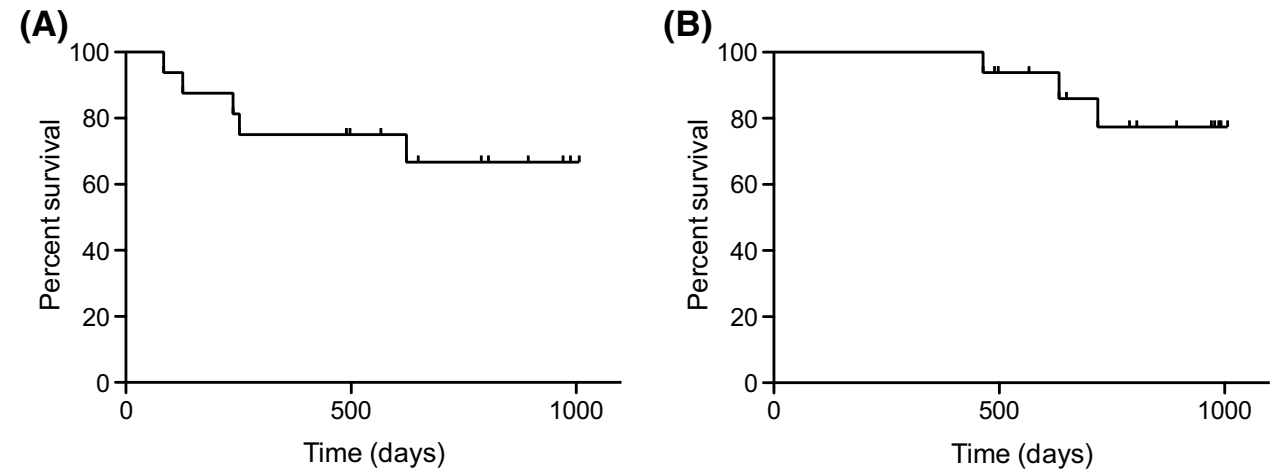

time (MST) was also not reached, and the 2.5-year survival rate was $77.3 \%$ (95\% CI 44.3-92.2\%).

\section{Univariate analysis}

When analyzing prognostic factors for OS, univariate analysis using the log-rank test confirmed well-known prognostic parameters such as PS $(P=0.00569)$, albu$\min (P=0.0000323)$, ISS $(P=0.0123)$ and del 17 $(P=0.00157)$ to be of prognostic relevance in our patient cohort (Table 5). Regarding best overall response during 6 courses of sVRD, OS was negatively influenced by PR compared with sCR, CR or VGPR $(P=0.0334)$. Furthermore, disease progression as a reason for discontinuation of sVRD had a negative impact on OS in comparison with other reasons ( $P=0.0000374)$. These results indicated that refractoriness to the sVRD regimen could not be easily rescued by any post-study therapies. Nevertheless, none of the variables selected on univariate analysis was an independent prognostic marker for OS in the Cox proportional hazards regression model since the number of patients for multivariate analysis was small.

\section{Safety}

One dose modification of dexamethasone from 40 to $20 \mathrm{mg} /$ day was required because of grade 2 hypertension after the 3 rd course of sVRD. One patient had discontinued 
Table 5 Univariate analysis (log-rank test) of prognostic factors for overall survival

\begin{tabular}{|c|c|c|}
\hline Characteristic & Number of cases & $P$ value \\
\hline \multicolumn{3}{|l|}{ Sex } \\
\hline Male & 11 & 0.27 \\
\hline Female & 5 & \\
\hline \multicolumn{3}{|l|}{ Age (year) } \\
\hline$>67$ & 7 & 0.766 \\
\hline$\leq 67$ & 9 & \\
\hline \multicolumn{3}{|l|}{ PS } \\
\hline$\geq 2$ & 2 & 0.00569 \\
\hline$<2$ & 14 & \\
\hline \multicolumn{3}{|c|}{ Beta-2 microglobulin (mg/L) } \\
\hline$\geq 2.5$ & 3 & 0.507 \\
\hline$<2.5$ & 13 & \\
\hline \multicolumn{3}{|l|}{ Albumin $(\mathrm{g} / \mathrm{dL})$} \\
\hline$<3.5$ & 2 & 0.0000323 \\
\hline$\geq 3.5$ & 14 & \\
\hline \multicolumn{3}{|l|}{ ISS stage at enrollment } \\
\hline II, III & 3 & 0.0123 \\
\hline I & 13 & \\
\hline \multicolumn{3}{|l|}{ del 13} \\
\hline Yes & 4 & 0.371 \\
\hline No & 5 & \\
\hline \multicolumn{3}{|l|}{$4(4 ; 14)$} \\
\hline Yes & 3 & 0.386 \\
\hline No & 4 & \\
\hline \multicolumn{3}{|l|}{ del 17} \\
\hline Yes & 1 & 0.00157 \\
\hline No & 10 & \\
\hline \multicolumn{3}{|l|}{ Status at enrollment } \\
\hline PR & 9 & 0.0731 \\
\hline sCR, CR, VGPR & 7 & \\
\hline \multicolumn{3}{|c|}{ Best overall response during 6 courses } \\
\hline PR & 8 & 0.0334 \\
\hline sCR, CR, VGPR & 8 & \\
\hline \multicolumn{3}{|c|}{ Reason for discontinuation } \\
\hline Disease progression & 3 & 0.0000374 \\
\hline Others & 13 & \\
\hline \multicolumn{3}{|c|}{ Second primary malignancy } \\
\hline Yes & 2 & 0.296 \\
\hline No & 14 & \\
\hline
\end{tabular}

all study drugs because of grade 2 pneumonia after 6 courses of sVRD. AEs are summarized in Table 6. Grade 2 sensory neuropathy was reported in two patients; however, neuropathy occurred in each patient during their induction therapies and lasted thereafter with no worsening. Grade 2 neutropenia occurred in 2 patients, pneumonia in 2 , thrombocytopenia in 1 , hypertension in 1 , constipation in 1 and
Table 6 Adverse events

\begin{tabular}{llll}
\hline Adverse events & $\begin{array}{l}\text { Grade } 2 \\
n(\%)\end{array}$ & $\begin{array}{l}\text { Grade } 3 \\
n(\%)\end{array}$ & $\begin{array}{l}\text { Grade 4 } \\
n(\%)\end{array}$ \\
\hline Sensory neuropathy & $2(12.5)^{\mathrm{a}}$ & $0(0)$ & $0(0)$ \\
Neutropenia & $2(12.5)$ & $0(0)$ & $0(0)$ \\
Pneumonia & $2(12.5)$ & $0(0)$ & $0(0)$ \\
Thrombocytopenia & $1(6.3)$ & $0(0)$ & $0(0)$ \\
Hypertension & $1(6.3)$ & $0(0)$ & $0(0)$ \\
Constipation & $1(6.3)$ & $0(0)$ & $0(0)$ \\
Anemia & $1(6.3)$ & $0(0)$ & $0(0)$ \\
\hline a Preexisting neuropathy with no worsening
\end{tabular}

anemia in 1 . There were no grade 3 or 4 hematologic or nonhematologic AEs.

\section{Secondary primary malignancies}

After enrollment, 2 new hematologic malignancies, i.e., ALL in one patient and MDS in another patient, were diagnosed (Table 7). The time from diagnosis to enrollment was 38 or 60 months in the patient with ALL or MDS, respectively. The former patient was pretreated with vincristine, adriamycin and dexamethasone (VAD) and autologous HSCT (ASCT) and then underwent 18 courses of sVRD treatment. He discontinued sVRD due to the occurrence of ALL. He has been alive after the standard induction/consolidation chemotherapy for ALL and allogeneic HSCT. The latter patient was pretreated with VAD and bortezomib plus dexamethasone (Bd) and then underwent sVRD treatment. After the 7th course, the sVRD regimen was stopped due to disease progression. The combination regimen of melphalan, prednisone and lenalidomide (MPR) was introduced as a post-study therapy, and a gradual dose reduction of melphalan was needed because of progressive pancytopenia. The diagnosis of MDS was made based on the findings of bone marrow aspiration. He finally died of PD.

\section{Discussion}

Three previous reports investigated the regimen of bortezomib-lenalidomide-dexamethasone in the consolidation/ maintenance setting [21, 23, 27] (Table 8). In the report by Roussel et al. [23], previously untreated patients were treated with the VRD regimen, as an induction therapy for three cycles and a consolidation therapy for two cycles after ASCT. Nooka et al. [27] treated previously untreated patients with the VRD regimen as a maintenance therapy after ASCT for three years. Richardson et al. [21] administered the VRD regimen in relapsed/refractory patients, as a re-induction therapy for eight cycles and a maintenance 
Table 7 Second primary malignancies (SPMs)

\begin{tabular}{lllcl}
\hline SPM & $n(\%)$ & Time to enrollment (months) & sVRD (courses) & Prior therapies \\
\hline Acute lymphoblastic leukemia & $1(6.3)$ & 38 & 18 & VAD, ASCT \\
Myelodysplastic syndrome & $1(6.3)$ & 60 & 7 & VAD, Bd \\
\hline
\end{tabular}

$V A D$ vincristine, adriamycin and dexamethasone, ASCT autologous hematopoietic stem cell transplantation, $B d$ bortezomib plus dexamethasone

Table 8 VRD regimens used for consolidation and/or maintenance

\begin{tabular}{|c|c|c|c|c|}
\hline & $\begin{array}{l}\text { Roussel et al. J Clin Oncol } \\
2014 \text { (23) }\end{array}$ & $\begin{array}{l}\text { Nooka et al. Leukemia } 2014 \\
\text { (27) }\end{array}$ & $\begin{array}{l}\text { Richardson et al. Blood } 2014 \\
\text { (21) }\end{array}$ & Our trial \\
\hline Patients & Previously untreated & $\begin{array}{l}\text { Previously untreated (high- } \\
\text { risk) }\end{array}$ & $\begin{array}{l}\text { Relapsed/ } \\
\text { refractory }\end{array}$ & $\geq \mathrm{PR}$ after any induction \\
\hline Phases of treatment & $\begin{array}{l}\text { Induction } \\
3 \text { cycles } \\
\text { Consolidation (after ASCT) } \\
2 \text { cycles }\end{array}$ & $\begin{array}{l}\text { Maintenance (after ASCT) } \\
3 \text { years }\end{array}$ & $\begin{array}{l}\text { Induction } \\
8 \text { cycles } \\
\text { Maintenance } \\
\text { until PD }\end{array}$ & $\begin{array}{l}\text { Consolidation/maintenance } \\
\geq 6 \text { cycles }\end{array}$ \\
\hline Cycle length & 21 days & 28 days & 21 days & 28 days \\
\hline Bortezomib & $\begin{array}{l}1.3 \mathrm{mg} / \mathrm{m}^{2} \\
\text { IV } \\
\text { days } 1,4,8,11\end{array}$ & $\begin{array}{l}1.3 \mathrm{mg} / \mathrm{m}^{2} \\
\text { IV or SC } \\
\text { days } 1,8,15,22\end{array}$ & $\begin{array}{l}1.0 \mathrm{mg} / \mathrm{m}^{2} \\
\text { IV } \\
\text { days } 1,4,8,11\end{array}$ & $\begin{array}{l}1.3 \mathrm{mg} / \mathrm{m}^{2} \\
\mathrm{SC} \\
\text { days } 1,15\end{array}$ \\
\hline$<$ Average $>$ & $1.7 \mathrm{mg} / \mathrm{m}^{2} /$ week & $1.3 \mathrm{mg} / \mathrm{m}^{2} /$ week & $1.3 \mathrm{mg} / \mathrm{m}^{2} /$ week & $0.7 \mathrm{mg} / \mathrm{m}^{2} /$ week \\
\hline Lenalidomide & $\begin{array}{l}25 \mathrm{mg} / \mathrm{body} \\
\text { days } 1-14\end{array}$ & $\begin{array}{l}10 \mathrm{mg} / \mathrm{body} \\
\text { days } 1-21\end{array}$ & $\begin{array}{l}15 \mathrm{mg} / \mathrm{body} \\
\text { days } 1-14\end{array}$ & $\begin{array}{l}10 \mathrm{mg} / \mathrm{body} \\
\text { days } 1-21\end{array}$ \\
\hline$<$ Average $>$ & $17 \mathrm{mg} /$ day & $7.5 \mathrm{mg} /$ day & $10 \mathrm{mg} /$ day & $7.5 \mathrm{mg} /$ day \\
\hline Dexamethasone & $\begin{array}{l}40 \mathrm{mg} / \text { body } \\
\text { days } 1,8,15\end{array}$ & $\begin{array}{l}40 \mathrm{mg} / \text { body } \\
\text { days } 1,8,15,22\end{array}$ & $\begin{array}{l}40 \mathrm{mg} / \text { body } \\
\text { days } 1,2,4,5,8,9,11,12 \\
\text { (cycles } 1-4)\end{array}$ & $\begin{array}{l}40 \mathrm{mg} / \mathrm{body} \\
\text { days } 1,8,15,22\end{array}$ \\
\hline$<$ Average $>$ & $40 \mathrm{mg} /$ week & $40 \mathrm{mg} /$ week & 107 mg/week & $40 \mathrm{mg} /$ week \\
\hline PN (G1-2) & $55 \%$ & N.D. & $53 \%^{a}$ & $13 \%^{b}$ \\
\hline NP (G3-4) & $35 \%$ & N.D. & $30 \%$ & $0 \%$ \\
\hline $\mathrm{TCP}(\mathrm{G} 3-4)$ & $13 \%$ & N.D. & $22 \%$ & $0 \%$ \\
\hline Dose modification & $39 \%$ & $40 \%$ & $66 \%$ & $7 \%$ \\
\hline ORR & $100 \%$ & $100 \%$ & $64 \%$ & $100 \%$ \\
\hline OS & $100 \%$ (3 years) & $93 \%$ (3 years) & $65 \%$ (2 years) & $77 \%$ (2.5 years) \\
\hline
\end{tabular}

$P D$ progressive disease, $I V$ intravenous, $S C$ subcutaneous, $A S C T$ autologous hematopoietic stem cell transplantation, $P R$ partial response, $P N$ peripheral neuropathy, N.D. not described, $N P$ neutropenia, $T C P$ thrombocytopenia, $O R R$ overall response rate, $O S$ overall survival

a $6 / 36$ patients had $\mathrm{PN}$ at baseline

b $2 / 2$ patients had $\mathrm{PN}$ at baseline

therapy until PD. In our trial, patients with at least PR after any induction therapy were enrolled to receive our SVRD regimen as a consolidation/maintenance therapy for at least 6 cycles.

Even though the same terminology of VRD was used in the three previous reports, the dosages of bortezomib and lenalidomide were not the same. On average, Roussel et al. [23], Nooka et al. [27] and Richardson et al. [21] administered bortezomib at $1.7,1.3$ or $1.3 \mathrm{mg} / \mathrm{m}^{2} /$ week and lenalidomide at $17,7.5$ or $10 \mathrm{mg} /$ day, respectively. In our trial, bortezomib and lenalidomide were administered at $0.7 \mathrm{mg} /$ $\mathrm{m}^{2} /$ week and $7.5 \mathrm{mg} / \mathrm{day}$, respectively. The dosages of bortezomib and lenalidomide used in our trial were the lowest compared with those reported by Roussel et al. [23], Nooka et al. [27] and Richardson et al. [21]. Improvement in tolerability and the preservation of efficacy compared with the three previous reports were important issues in our trial.

The most common toxicities related to the VRD regimen were neurologic and hematologic. Grade 1-2 peripheral neuropathy (PN) was reported in 55 or $53 \%$ of patients by Roussel et al. [23] and Richardson et al. [21], respectively. In our trial, two patients (13\%) experienced grade $2 \mathrm{PN}$; however, their neuropathy was due to prior usage of bortezomib with no worsening after enrollment in our study. A lower occurrence of PN possibly reflects the lower dosage of bortezomib at $0.7 \mathrm{mg} / \mathrm{m}^{2} /$ week. In addition, 
subcutaneous administration of bortezomib instead of intravenous injection may reduce the occurrence of PN since it is well known that PN of any grade was significantly less common with subcutaneous than with intravenous administration [28, 29]. As for hematologic toxicities, grade 3-4 neutropenia (NP) (35 or $30 \%$ ) and thrombocytopenia (TCP) (13 or $22 \%)$ were reported by Roussel et al. [23] and Richardson et al. [21], respectively. In our trial, there were no cases of grade 3-4 NP and TCP, possibly reflecting the lower dosage of lenalidomide at $7.5 \mathrm{mg}$ /day on average.

Furthermore, the tolerability of each VRD regimen could be evaluated by the necessity of dose modification. In the reports by Roussel et al. [23], Nooka et al. [27] and Richardson et al. [21], at least one dose modification among bortezomib, lenalidomide and dexamethasone was required in 39, 40 or $66 \%$ of patients, respectively. On the other hand, dose modification was required in only one patient $(7 \%)$ in our trial: The dose of dexamethasone was reduced from 40 to $20 \mathrm{mg} /$ week due to grade 2 hypertension after the 3rd course of sVRD. Especially, in the report by Roussel et al. [23], patients were previously untreated and relatively young (range 33-65 years) compared with our patients (range 53-78 years); however, almost $40 \%$ of patients could not complete five courses with their dosage of bortezomib $\left(1.7 \mathrm{mg} / \mathrm{m}^{2} /\right.$ week $)$ and lenalidomide $(17 \mathrm{mg} /$ day). All of our patients could complete six courses of our sVRD regimen. Taking AEs and dose modification into consideration, the dosage of bortezomib $\left(0.7 \mathrm{mg} / \mathrm{m}^{2} /\right.$ week $)$ and lenalidomide $(7.5 \mathrm{mg} /$ day $)$ in our trial might be well rationalized.

As for the efficacy of each VRD regimen, the ORR could be comparable. In the reports by Roussel et al. [23], Nooka et al. [27] and Richardson et al. [21], the ORR was 100,100 or $64 \%$, respectively. Further, OS was $100 \%$ (3 years), $93 \%$ (3 years) or $65 \%$ ( 2 years), respectively. The ORR and OS in the report by Richardson et al. [21] were lower than those in the reports by Roussel et al. [23] and Nooka et al. [27] since the patients in the study of Richardson et al. [21] were relapsed/refractory. In our trial, the ORR and OS were 100 and $77 \%$ (2.5 years), respectively. Needless to say, it is difficult to precisely compare the ORR and OS of our trial with those of other three reports because of many biases. Nevertheless, it can be speculated that the low dosage of bortezomib and lenalidomide in our trial did not necessarily result in decreased efficacy. We conclude that the dosage of bortezomib and lenalidomide in our SVRD regimen may be able to reduce AEs and have preserved efficacy simultaneously in the consolidation/ maintenance setting.

In conclusion, our sVRD regimen as a consolidation/ maintenance therapy was well tolerable and highly effective in patients with MM who achieved at least PR after any induction therapy. These results seem comparable to those of the other VRD regimens previously published [21, 23, 27] and hence support the rationale for our ongoing phase II study of the sVRD regimen in previously untreated transplant-ineligible patients with MM.

Acknowledgments This work was written on behalf of the Hokkaido Clinical Hematology Study Group (HCHSG). We thank the patients who participated in this trial and their families; the study coordinators and the support staff at the clinical sites.

\section{Compliance with ethical standards}

Conflict of interest All authors declare no conflicts of interest.

Ethical approval All procedures performed in studies involving human participants were in accordance with the ethical standards of the institutional and/or national research committee and with the 1964 Declaration of Helsinki and its later amendments or comparable ethical standards.

Open Access This article is distributed under the terms of the Creative Commons Attribution 4.0 International License (http://creativecommons.org/licenses/by/4.0/), which permits unrestricted use, distribution, and reproduction in any medium, provided you give appropriate credit to the original author(s) and the source, provide a link to the Creative Commons license, and indicate if changes were made.

\section{References}

1. Palumbo A, Mina R, Cerrato C, Cavallo F (2013) Role of consolidation/maintenance therapy in multiple myeloma. Clin Lymphoma Myeloma Leuk 13(Suppl 2):S349-S354. doi:10.1016/j. clml.2013.05.009

2. Palumbo A, Anderson K (2011) Multiple myeloma. N Engl J Med 364:1046-1060. doi:10.1056/NEJMra1011442

3. Attal M, Harousseau J-L, Leyvraz S et al (2006) Maintenance therapy with thalidomide improves survival in patients with multiple myeloma. Blood 108:3289-3294. doi:10.1182/ blood-2006-05-022962

4. Spencer A, Prince HM, Roberts AW et al (2009) Consolidation therapy with low-dose thalidomide and prednisolone prolongs the survival of multiple myeloma patients undergoing a single autologous stem-cell transplantation procedure. J Clin Oncol 27:1788-1793. doi:10.1200/JCO.2008.18.8573

5. Barlogie B, Tricot G, Anaissie E et al (2006) Thalidomide and hematopoietic-cell transplantation for multiple myeloma. N Engl J Med 354:1021-1030. doi:10.1056/NEJMoa053583

6. Morgan GJ, Gregory WM, Davies FE et al (2012) The role of maintenance thalidomide therapy in multiple myeloma: MRC myeloma IX results and meta-analysis. Blood 119:7-15. doi:10.1182/blood-2011-06-357038

7. Ludwig H, Adam Z, Tóthová E et al (2010) Thalidomide maintenance treatment increases progression-free but not overall survival in elderly patients with myeloma. Haematologica 95:15481554. doi:10.3324/haematol.2009.020586

8. Lokhorst HM, van der Holt B, Zweegman S et al (2010) A randomized phase 3 study on the effect of thalidomide combined with adriamycin, dexamethasone, and high-dose melphalan, followed by thalidomide maintenance in patients with multiple myeloma. Blood 115:1113-1120. doi:10.1182/blood-2009-05-222539 
9. Palumbo A, Hajek R, Delforge M et al (2012) Continuous lenalidomide treatment for newly diagnosed multiple myeloma. $\mathrm{N}$ Engl J Med 366:1759-1769. doi:10.1056/NEJMoa1112704

10. McCarthy PL, Owzar K, Hofmeister CC et al (2012) Lenalidomide after stem-cell transplantation for multiple myeloma. $\mathrm{N}$ Engl J Med 366:1770-1781. doi:10.1056/NEJMoa1114083

11. Attal M, Lauwers-Cances V, Marit G et al (2012) Lenalidomide maintenance after stem-cell transplantation for multiple myeloma. N Engl J Med 366:1782-1791. doi:10.1056/ NEJMoa1114138

12. Palumbo A, Gay F, Falco P et al (2010) Bortezomib as induction before autologous transplantation, followed by lenalidomide as consolidation-maintenance in untreated multiple myeloma patients. J Clin Oncol 28:800-807. doi:10.1200/ JCO.2009.22.7561

13. Sonneveld P, Schmidt-Wolf IGH, van der Holt B et al (2012) Bortezomib induction and maintenance treatment in patients with newly diagnosed multiple myeloma: results of the randomized phase III HOVON-65/GMMG-HD4 trial. J Clin Oncol 30:2946-2955. doi:10.1200/JCO.2011.39.6820

14. Palumbo A, Bringhen S, Rossi D et al (2010) Bortezomibmelphalan-prednisone-thalidomide followed by maintenance with bortezomib-thalidomide compared with bortezomib-melphalan-prednisone for initial treatment of multiple myeloma: a randomized controlled trial. J Clin Oncol 28:5101-5109. doi:10.1200/JCO.2010.29.8216

15. Mateos M-V, Oriol A, Martínez-López J et al (2010) Bortezomib, melphalan, and prednisone versus bortezomib, thalidomide, and prednisone as induction therapy followed by maintenance treatment with bortezomib and thalidomide versus bortezomib and prednisone in elderly patients with untreated multiple myeloma. Lancet Oncol 11:934-941. doi:10.1016/ S1470-2045(10)70187-X

16. Ladetto M, Pagliano G, Ferrero S et al (2010) Major tumor shrinking and persistent molecular remissions after consolidation with bortezomib, thalidomide, and dexamethasone in patients with autografted myeloma. J Clin Oncol 28:2077-2084. doi:10.1200/JCO.2009.23.7172

17. Cavo M, Pantani L, Petrucci MT et al (2012) Bortezomib-thalidomide-dexamethasone is superior to thalidomide-dexamethasone as consolidation therapy after autologous hematopoietic stem cell transplantation in patients with newly diagnosed multiple myeloma. Blood 120:9-19. doi:10.1182/blood-2012-02-408898

18. Kikuchi J, Koyama D, Mukai HY, Furukawa Y (2014) Suitable drug combination with bortezomib for multiple myeloma under stroma-free conditions and in contact with fibronectin or bone marrow stromal cells. Int J Hematol 99:726-736. doi:10.1007/ s12185-014-1573-3

19. Stewart AK, Richardson PG, San-Miguel JF (2009) How I treat multiple myeloma in younger patients. Blood 114:5436-5443. doi:10.1182/blood-2009-07-204651
20. Richardson PG, Weller E, Jagannath S et al (2009) Multicenter, phase I, dose-escalation trial of lenalidomide plus bortezomib for relapsed and relapsed/refractory multiple myeloma. J Clin Oncol 27:5713-5719. doi:10.1200/JCO.2009.22.2679

21. Richardson PG, Xie W, Jagannath S et al (2014) A phase 2 trial of lenalidomide, bortezomib, and dexamethasone in patients with relapsed and relapsed/refractory myeloma. Blood 123:14611469. doi:10.1182/blood-2013-07-517276

22. Richardson PG, Weller E, Lonial S et al (2010) Lenalidomide, bortezomib, and dexamethasone combination therapy in patients with newly diagnosed multiple myeloma. Blood 116:679-686. doi:10.1182/blood-2010-02-268862

23. Roussel M, Lauwers-Cances V, Robillard N et al (2014) Frontline transplantation program with lenalidomide, bortezomib, and dexamethasone combination as induction and consolidation followed by lenalidomide maintenance in patients with multiple myeloma: a phase II study by the Intergroupe Francophone du Myélo. J Clin Oncol 32:2712-2717. doi:10.1200/ JCO.2013.54.8164

24. Dimopoulos MA, Beksac M, Benboubker L et al (2013) Phase II study of bortezomib-dexamethasone alone or with added cyclophosphamide or lenalidomide for sub-optimal response as second-line treatment for patients with multiple myeloma. Haematologica 98:1264-1272. doi:10.3324/haematol.2013.084376

25. Dimopoulos MA, Kastritis E, Christoulas D et al (2010) Treatment of patients with relapsed/refractory multiple myeloma with lenalidomide and dexamethasone with or without bortezomib: prospective evaluation of the impact of cytogenetic abnormalities and of previous therapies. Leukemia 24:1769-1778. doi:10.1038/leu.2010.175

26. Kanda Y (2013) Investigation of the freely available easy-to-use software "EZR" for medical statistics. Bone Marrow Transplant 48:452-458. doi:10.1038/bmt.2012.244

27. Nooka AK, Kaufman JL, Muppidi S et al (2014) Consolidation and maintenance therapy with lenalidomide, bortezomib and dexamethasone (RVD) in high-risk myeloma patients. Leukemia 28:690-693. doi:10.1038/leu.2013.335

28. Arnulf B, Pylypenko H, Grosicki S et al (2012) Updated survival analysis of a randomized phase III study of subcutaneous versus intravenous bortezomib in patients with relapsed multiple myeloma. Haematologica 97:1925-1928. doi:10.3324/ haematol.2012.067793

29. Moreau P, Pylypenko H, Grosicki S et al (2011) Subcutaneous versus intravenous administration of bortezomib in patients with relapsed multiple myeloma: a randomised, phase 3, noninferiority study. Lancet Oncol 12:431-440. doi:10.1016/ S1470-2045(11)70081-X 